\title{
Energy integration of industrial sites with heat exchange restrictions
}

\author{
Helen Becker, Luc Girardin, François Maréchal \\ Industrial Energy Systems Laboratory (LENI), Ecole Polytechnique Fédérale de Lau- \\ sanne, CH-1015 Lausanne, Switzerland, helen.becker@epfl.ch
}

\begin{abstract}
Process integration methods aim at identifying options for heat recovery and optimal energy conversion in industrial processes. By applying pinch analysis methods, the first step is to calculate the maximum heat recovery between cold and hot streams. The second step consists in designing the corresponding heat recovery exchanger network, based on a fixed list of streams.

For the heat cascade, it is assumed that any heat exchange between cold and hot streams is possible, but due to industrial constraints, in many cases, this assumption cannot be accepted in practice and it is necessary to impose restricted matches. This introduces energy penalties, which could be reduced by using intermediate heat transfer systems. This paper introduces a targeting method including industrial constraints to ensure feasible solutions for the heat exchanger network. Intermediate heat transfer systems are integrated so that restricted heat exchanges become possible and heat recovery penalties, created by those constraints, can be reduced.

The problem is formulated as a MILP problem, which considers not only restricted matches but also the optimal integration of the energy conversion system, like heat pumping and combined heat and power production.

The application of the method will be illustrated by an industrial example from the pulp and paper industry. The extension of the method to study the heat integration of semi batch processes will be discussed.
\end{abstract}

Keywords: pinch analysis method, utility integration, process design, process sub-systems, heat exchanger network

\section{Introduction}

Pinch analysis is a promising tool to optimize the energy efficiency of industrial processes. To realize the maximum heat recovery and the optimal integration of utilities to supply heating and cooling requirement, a heat exchanger network has to be designed, considering process and utility streams. One major drawback is the assumption that any hot stream can exchange heat with any cold stream. In reality, heat exchanges become difficult or even impossible, due to constraints such as the distance between streams or quality and/or security reasons, or due to system dynamics such as non-simultaneous operations.

The total site approach, presented by Klemeš et al. (1997), implicitly accounts restricted matches. The cold and hot streams, resulting from sub-systems without considering selfsufficient pockets, are separated graphically. The sub-systems can only exchange heat via the steam system; the heat recovery is calculated, but there is no systematic approach to define the members of sub-systems and the integration of the energy conversion units is not considered. Especially, the self-sufficient pockets are suppressed, which prevents the combined heat and power integration. Bagajewicz and Rodera (2001) propose a single 
heat belt, which exchanges heat between process plants by an intermediate fluid. Only for special cases ( 3 process plants) this problem is solved by using a MILP formulation. Forbidden matches between certain pairs of process streams are considered by Papoulias and Grossmann (1983). They propose a mathematical formulation to minimize the energy penalty (without integrating utility streams) and the heat exchanger network design with restricted matches. Also Cerda and Westerburg (1983) studied heat exchanger networks with restricted matches and propose an algorithm which imposes constraints disallowing in part or in total the matching of stream pairs. Maréchal and Kalitventzeff (1999) propose a MILP strategy, which integrates forbidden heat exchange connections as constraints in the targeting phase, and allows the integration of heat transfer fluids.

For solving a site scale process integration problem, this paper presents an extension of this MILP strategy and introduces the approach of process integration by sub-systems, which makes the practical implementation easier and considers restricted matches between sub-systems.

\section{Method}

The new methodology, proposed here, takes into account heat exchange restrictions at the targeting stage by dividing industrial plants into sub-systems. Heat can be exchanged inside a sub-system but no direct heat exchange with other sub-systems is allowed. The integration of a heat transfer system (e.g. hot water loop or steam network) gives the possibility of indirect heat exchange between sub-systems. The mass flows rates of the heat transfer fluids are optimized in order to minimize the cost of the energy penalty.

The problem is solved in three steps. In the first step, a MILP problem is formulated to define the composite curves with heat exchange restrictions, that represent the necessary enthalpy-temperature profiles for the heat transfer system. Then, a second MILP problem is solved to target the integration of heat transfer fluids together with energy conversion systems. The heat load distribution problem (HLD), proposed by Maréchal and Kalitventzeff (1989), is then adapted to incorporate the definition of sub-systems. The resolution of the HLD problem becomes much easier and corresponds to the first step of the heat exchanger network design. The major advantages of the presented method are:

- The process is divided into sub-systems (more realist than just heat restriction constraints for two streams); heat exchange inside sub-systems is favored.

- Contrary to the total site integration methodology, self-sufficient pockets are not suppressed. This allows the maximization of the combined heat and power production.

- The design of the heat exchanger network becomes easier and more flexible and implicitly includes topological constraints.

- Simultaneous optimization of the utility integration and the heat transfer system defines the complete list of streams and allows the HEN design.

- The combinatorial nature of the HEN design is included.

\section{Optimization algorithm}

The objective is to minimize the operating costs (equation (1)). $\dot{E}_{f u e l}^{+}$is the energy delivered by the fuel (e.g. natural gas) and $\dot{E}_{e l}$ is the electricity demand ${ }^{(+)}$or excess $^{(-)}$of the 
process. For the electricity cost, $c_{e l}^{+}$is the purchase cost and $c_{e l}^{-}$is the selling price. $c_{f u e l}$ is the fuel price.

$$
F_{o b j}=\min \left(c_{\text {fuel }} \dot{E}_{\text {fuel }}^{+}+c_{e l}^{+} \dot{E}_{e l}^{+}-c_{e l}^{-} \dot{E}_{e l}^{-}\right)
$$

The normal heat cascade for each temperature interval $\mathrm{k}$ is given by equation (2), where $\dot{M}$ is the mass flow rate $[\mathrm{kg} / \mathrm{s}]$ and $q$ is the heat load per mass flow $[\mathrm{MJ} / \mathrm{kg}]$. The subscripts "c" and " $h "$ indicate cold and hot streams respectively and $\mathrm{k}$ refers to the temperature interval $\mathrm{k}$ of the heat cascade. $R_{k}$ is the cascaded heat from the temperature interval $\mathrm{k}$ to the lower temperature intervals.

$$
\begin{gathered}
\sum_{h_{k}=1}^{n_{h, k}} \dot{M}_{h, k} q_{h, k}-\sum_{c_{k}=1}^{n_{c, k}} \dot{M}_{c, k} q_{c, k}+\dot{R}_{k+1}-\dot{R}_{k}=0 \quad \forall k=1 \ldots, n_{k} \\
R_{k} \geq 0 \quad \forall k=1 \ldots, n_{k}
\end{gathered}
$$

When the industrial plant is divided into sub-systems following equations (4) - (7) are added to take account of heat exchange restrictions:

$$
\begin{aligned}
& \sum_{h_{s, k}=1}^{n_{h, s, k}} \dot{M}_{h, s, k} q_{h, s, k}-\sum_{c_{s, k}=1}^{n_{c, s, k}} \dot{M}_{c, s, k} q_{c, s, k}+\dot{Q}_{h t s, s, k}^{-}-\dot{Q}_{h t s, s, k}^{+}+\dot{R}_{s, k+1}-\dot{R}_{s, k}=0 \\
& \forall k=1 \ldots, n_{k}, \forall s=1 \ldots, n_{s} \\
& \dot{R}_{s, k} \geq 0 \quad \forall k=1 \ldots, n_{k}, \forall s=1 \ldots, n_{s}
\end{aligned}
$$

For each sub-system (s) the heat cascade is given by equation (4). When a sub-system has a deficit or a surplus of heat in the temperature interval $\mathrm{k}$, the heat is supplied from the heat transfer system $\left(Q_{h t s, s, k}^{-}\right)$or respectively removed by the heat transfer system $\left(Q_{h t s, s, k}^{+}\right)$. To ensure that heat is cascaded correctly, a second set of equations is necessary. Equation (6) express the heat balance of the hot streams and equation (7) express the heat balance of the cold streams in the heat transfer system $(h t s)$. The flow rates of the heat transfer fluids have to be optimized in order to satisfy the remaining heat demand of all sub-systems.

$$
\begin{gathered}
\sum_{h=1}^{n_{h, h t s, k}} \dot{M}_{h, h t s, k} q_{h, h t s, k}+\dot{R}_{h t s, k+1}-\dot{R}_{h t s, k}-\sum_{s=1}^{n_{s}} \dot{Q}_{h t s, s, k}^{-} \geq 0 \quad \forall k=1 \ldots, n_{k} \\
-\sum_{c=1}^{n_{c, h t s, k}} \dot{M}_{c, h t s, k} q_{c, h t s, k}+\dot{R}_{h t s, k+1}-\dot{R}_{h t s, k}+\sum_{s=1}^{n_{s}} \dot{Q}_{h t s, s, k}^{+} \geq 0 \quad \forall k=1 \ldots, n_{k}
\end{gathered}
$$

\section{Numerical example - drying process in paper industry}

The humid pulp is first preheated and enters then in the dryer unit. Steam satisfies a big part of the heat demand. The hot air also introduces heat to the dryer but its main function is to evacuate the evaporated water from the pulp. Possible heat recuperation is modeled by a humid air stream which has to be cooled down to the final temperature of $30^{\circ} \mathrm{C}$. The list of involved streams is given in table 1 .

The pulping unit, drying unit and the boiler are considered as sub-systems. This means, that the heat demand of sub-system 1 has to be satisfied by the heat transfer system, even if the excess heat of sub-system 2 is big enough to satisfy this demand. The penalty of this constraint can be visualized in the integrated composite curve of the utility system (figure 2a), calculated with the constraint and without heat transfer fluids.

In order to reduce or eliminate this penalty, intermediate fluids can be used in the heat transfer system. Figure $2 \mathrm{~b}$ shows the integrated composite curve obtained by solving the 


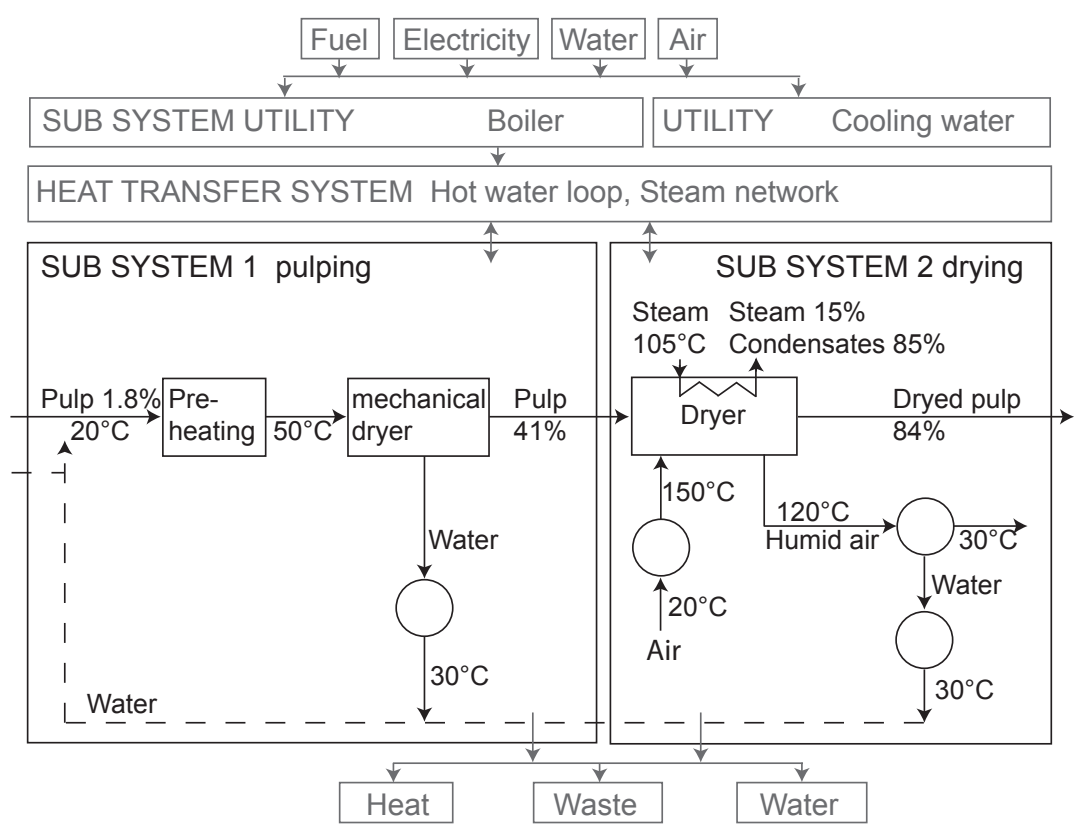

Figure 1: Representation of process

Table 1: Hot and cold streams of the process

\begin{tabular}{llllll}
\hline Sub-system & $\begin{array}{l}\text { Name } \\
{\left[{ }^{\circ} \mathrm{C}\right]}\end{array}$ & $\begin{array}{l}\mathrm{T}_{\text {in }} \\
{\left[{ }^{\circ} \mathrm{C}\right]}\end{array}$ & $\begin{array}{l}\mathrm{T}_{\text {out }} \\
{[\mathrm{kW}]}\end{array}$ & Heat Load & Remark \\
\hline \hline \multirow{2}{*}{ pulping } & $\mathrm{C} 1$ & 20 & 50 & 11262 & Preheating \\
\cline { 2 - 6 } & $\mathrm{H} 2$ & 50 & 30 & -7297 & water cooling \\
\hline \hline \multirow{5}{*}{ drying } & $\mathrm{C} 5$ & 20 & 150 & 664 & Air heating \\
\cline { 2 - 6 } & $\mathrm{C} 6$ & 95 & 105 & 6058 & Steam demand \\
\cline { 2 - 6 } & $\mathrm{H} 3$ & 105 & 105 & -892 & Condensation of 15\% steam \\
\cline { 2 - 6 } & $\mathrm{H} 4$ & 105 & 95 & -112 & cooling of condensates \\
\cline { 2 - 6 } & $\mathrm{H} 9$ & 120 & 30 & -5319 & Humid air cooling \\
\hline \hline
\end{tabular}

problem with the integrated heat transfer system. Introducing a hot water loop, eliminates the penalty of the heat exchange restriction between the pulping and drying sub-system. Water is heated up from $25^{\circ} \mathrm{C}$ to $70^{\circ} \mathrm{C}$ with streams from the drying unit and heat is given back to the pulping unit by cooling down the water from $70^{\circ} \mathrm{C}$ to $25^{\circ} \mathrm{C}$. At higher temperatures a steam network is used for intermediate heat transfer between the boiler (steam production at 80 bar) and the process demand (steam utilization at 6 bar).

The heat load distribution is then calculated for each zone delimited by a pinch point. Figure 3 shows the heat load distribution of zone $1\left(12-103{ }^{\circ} \mathrm{C}\right)$, limited by the first pinch point at $103{ }^{\circ} \mathrm{C}$, obtained with the integrated heat transfer system (hot water loop and steam network). The temperatures on the graph correspond to the corrected temperatures. 

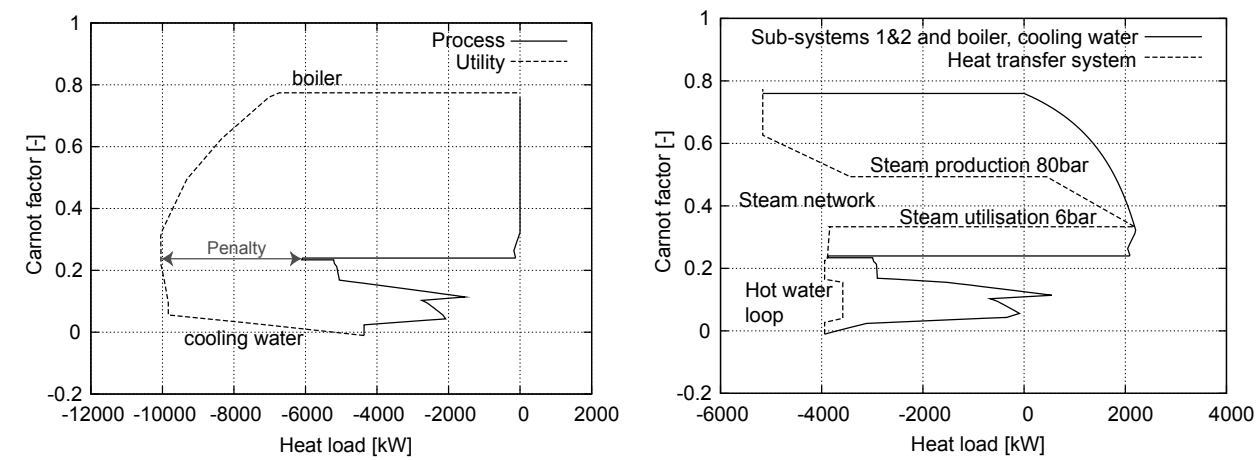

(a) Integrated composite curves of the utility system with (b) Integrated composite curves of heat transfer system constraints

Figure 2: Composite curves

Table 2: Results

\begin{tabular}{lllll}
\hline & Unit & $\begin{array}{l}\text { No } \\
\text { constraints }\end{array}$ & $\begin{array}{l}\text { With } \\
\text { constraints }\end{array}$ & $\begin{array}{l}\text { Constraints and } \\
\text { heat transfer system }\end{array}$ \\
\hline \hline Fuel consumption & {$[\mathrm{kW}]$} & 5981 & 9835 & 7233 \\
Cooling water consumption & {$[\mathrm{kW}]$} & 1618 & 5472 & 1648 \\
Electricity & {$[\mathrm{kW}]$} & & & 1190 \\
\hline
\end{tabular}

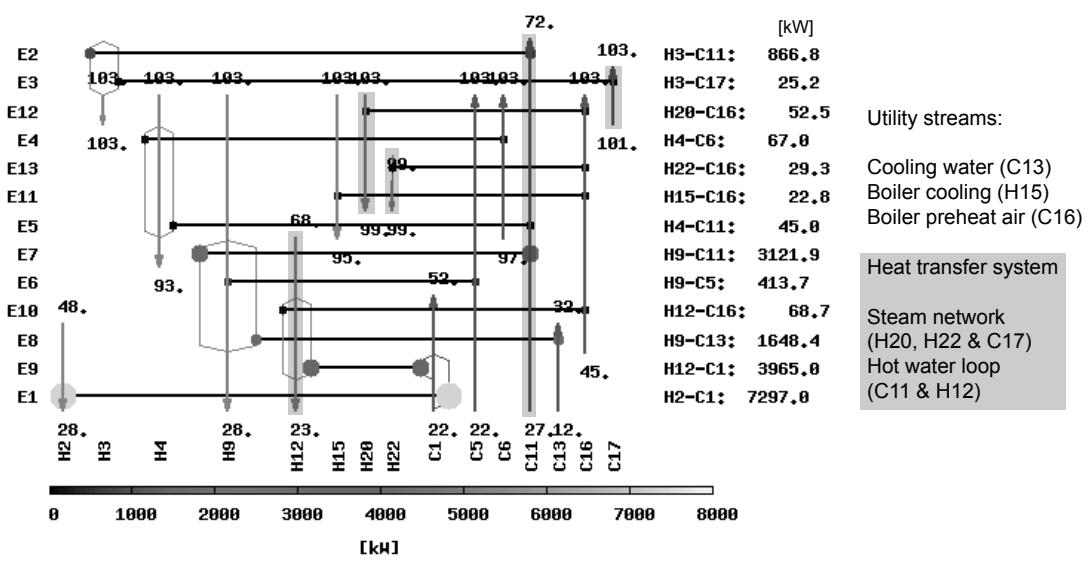

Figure 3: Heat load distribution with integrated heat transfer system

\section{Discussion and perspective}

Although, the method presented in this paper is illustrated by a simple example with three sub-systems, the method aims at solving complex examples with several sub-systems (e.g. process units with different locations or other industrial site constraints). The sub-system concept is also considered for calculating the integration of utility systems, for example the produced heat in a boiler cannot exchange directly with process streams, but a steam network makes the heat exchange possible. 
The method can also be used to solve batch problems (non simultaneously operations in one period) considering that during one operation step the streams cannot exchange directly with another operation step. In this case, the heat exchange between two batch operations of the same period requires the use of a heat transfer system that will be optimized by the proposed method. The batch operations can exchange heat by storing temporarily this heat in vessels.

This approach combined with the MILP formulation for combined heat and power integration allows one to solve rigorously the problem of site scale integration. The proposed method can also be added to the approach proposed by Maréchal and Kalitventzeff (2003) to solve the multi-period problems for site scale integration.

\section{Acknowledgements}

The authors wish to thank ECLEER for supporting this research and collaborating in its realization.

\section{References}

Bagajewicz, M. and Rodera, H. 2001. On the use of heat belts for energy integration across many plants in the total site. Canadian Journal of Chemical Engineering, 79(4):633-642.

Cerda, J. and Westerburg, A. W. 1983. Synthesizing heat exchanger networks having restricted stream/stream matches using transportation problem formulations. Chemical Engineering Science, 38(10):1723-1740.

Klemeš, J., Dhole, V., Raissi, K., Perry, S., and Puigjaner, L. 1997. Targeting and design methodology for reduction of fuel, power and $\mathrm{CO} 2$ on total sites. Applied Thermal Engineering, 17(8-10):993-1003.

Maréchal, F. and Kalitventzeff, B. 1989. Synep1: a methodology for energy integration and optimal heat exchanger network synthesis. Computers chemical Engineering, 13(4/5):603-610.

Maréchal, F. and Kalitventzeff, B. 1999. Restricted mataches and minimum cost of energy requirements: tools and methodology for producing pratical solutions. 2-nd Conference on Process Integration and Optimisation for Energy Saving and Pollution Reduction PRES'99.

Maréchal, F. and Kalitventzeff, B. 2003. Targeting the integration of multi-period utility systems for site scale process integration. Applied Thermal Engineering, 23:17631784.

Papoulias, S. A. and Grossmann, I. E. 1983. A structural optimization approach in process synthesis - ii. Computers and Chemical Engineering, 7(6):707-721. 